\title{
Correspondence regarding the Perspective "Addressing the importance of microplastic particles as vectors for long-range transport of chemical contaminants: perspective in relation to prioritizing research and regulatory actions"
}

\author{
Juliane Glüge ${ }^{1,2}$, Narain M. Ashta ${ }^{1}$, Dorte Herzke ${ }^{3,4}$, Laurent Lebreton ${ }^{5,6}$ and Martin Scheringer ${ }^{1,7^{*}}$ (D)
}

\begin{abstract}
Important clarifications regarding the long-range environmental transport of chemical additives contained in floating plastic debris are presented.
\end{abstract}

Keywords: Long-range transport, Microplastics, Plastic additives, Floating plastic, Plastic pollution

The Perspective article by Gouin [1] summarizes various aspects of the environmental long-range transport of plastic particles and non-polymeric chemicals, and also discusses the present knowledge about, and uncertainties associated with, the transport of microplastics (MPs) and additives contained in MPs. However, the article contains many misinterpretations and inaccuracies that lead to incorrect conclusions. We argue therefore that this Perspective should be seen as an expression of the author's personal point of view, but should not be used as a source of information in discussions about the longrange environmental transport (LRET) of chemical plastic additives. The shortcomings of the Perspective are:

1) Omission of meso- and macroplastics

\footnotetext{
* Correspondence: scheringer@usys.ethz.ch

'Institute of Biogeochemistry and Pollutant Dynamics, ETH Zürich, 8092 Zürich, Switzerland

${ }^{7}$ RECETOX, Masaryk University, 62500 Brno, Czech Republic

Full list of author information is available at the end of the article
}

The Perspective focuses mainly on MPs and overlooks that it is not only MPs that can carry chemicals. It is mentioned that degradation and fragmentation of larger plastic items is an important source of MPs, but the transport and fate of particles larger than $5 \mathrm{~mm}$ is not considered in the Perspective. However, more than three quarters of the plastic debris (by mass) in the Great Pacific Garbage Patch is larger than $5 \mathrm{~cm}$ [2]. Meso- and macroplastics are considerable vectors for chemical transport, and reducing the discussion to MPs distorts the overall picture. Even more importantly, is has been shown that MPs smaller than $1 \mathrm{~mm}$ may not be easily available for oceanic long-range transport [3-7]. This fact is ignored in the Perspective and results of studies that are cited are not related to the LRET of chemical contaminants because they focus primarily on particles smaller than $1 \mathrm{~mm}$ (e.g. Dibke et al. (2021) [8] and Schernewski et al. (2020) [9]).

2) Inappropriate consideration of adsorbed chemicals

\section{Springer Open}

( ) The Author(s). 2022 Open Access This article is licensed under a Creative Commons Attribution 4.0 International License, which permits use, sharing, adaptation, distribution and reproduction in any medium or format, as long as you give appropriate credit to the original author(s) and the source, provide a link to the Creative Commons licence, and indicate if changes were made. The images or other third party material in this article are included in the article's Creative Commons licence, unless indicated otherwise in a credit line to the material. If material is not included in the article's Creative Commons licence and your intended use is not permitted by statutory regulation or exceeds the permitted use, you will need to obtain permission directly from the copyright holder. To view a copy of this licence, visit http://creativecommons.org/licenses/by/4.0/. 
One of the main statements in the Perspective is "... I perceive that the weight-of-evidence supports exposure to POPs via the LRET of MPs to be minimal relative to other transport pathways, see for instance [24-27]." While the statement as such is not incorrect, citations 24 to 27 are Zarfl et al. (2010) [10], Bakir et al. (2016) [11], Gouin et al. (2011) [12], and Koelmans et al. (2016) [13], all of which address chemicals that are adsorbed to plastics. Here the author made a statement about adsorbed chemicals, creating the impression that it would also be relevant for chemicals used as additives in plastics. A key difference is that chemical additives are present in plastic in concentrations higher by several orders of magnitude than concentrations of adsorbed contaminants [14]. Conclusions, especially on the mass balance from studies that only look at adsorbed chemicals, are therefore not relevant and valid for chemical additives. This has already been pointed out by Andrade et al. (2021) [15], but is not mentioned in the Perspective. Andrade et al. have shown "that approximately $8,100-18,900 \mathrm{t}$ of various organic additives are transported with buoyant plastic matrices globally with a significant portion also transported to the Arctic. For many of these chemicals, long-range transport (LRT) by plastic as a carrier is their only means of travelling over long distances without degrading, resulting in plastic debris enabling the LRT of chemicals which otherwise would not reach polar environments with unknown consequences."

3) Particulate organic matter is not a good analogue to plastic to learn about LRET

It is mentioned in the Perspective that particulate organic matter (POM) has a density and particle size that is similar to that of MPs and that "hydrological factors that influence the fate of POM in these systems, has the potential to influence the fate of the MPs in a similar manner." This might be correct for shorter time periods. However, POM is biodegradable and will therefore not serve as a vector for the LRET of chemicals [16].

\section{4) View on leaching of plastic additives too narrow}

The first part of the section "Does plastic represent a source of exposure to plastic-additive chemicals" discusses the diffusion and evaporation of plastic additives out of plastic into air. In comparison to these very detailed explanations, leaching of plastic additives into water or exposed organisms is not described at all (water) or only very briefly (exposed organisms). Especially for very hydrophobic substances, however, leaching into fat and oil is very relevant and clearly more important than diffusion into air. It is therefore necessary to also consider leaching in the gastrointestinal tract of exposed organisms $[17,18]$. The cases presented in the Perspective, which are intended to show that ingestion of MPs does not represent a significant source of exposure relative to other exposure pathways, are misleading as they represent substances (nonylphenol and bisphenol A) that are metabolized in fish and probably also in other organisms $[19,20]$. The high concentrations found for bisphenol A and nonylphenol therefore do not result from bioaccumulation but from high exposure levels. This is different for substances such as UV-328 that are only slowly metabolized [21, 22]. Experimental results show here that leaching into digestive fluids of seabirds is a relevant exposure pathway $[17,18]$.

5) Inappropriate and unfounded criticism of the study by Andrade et al. (2021)

The Perspective attempts to debase the article by Andrade et al. (2021) [15] with incorrect statements. In the Perspective, it is stated that Andrade et al. (2021) used an average weight fraction of $5 \%$ for the total of chemical additives associated with plastic debris. However, this is not correct. Andrade et al. (2021) [15] used a range of $3 \%$ to $7 \%$. It is also stated in the Perspective that the weight fraction adopted by Andrade et al. (2021) [15] is likely skewed due to the higher weight fractions of additives associated with polyvinylchloride (PVC). However, Andrade et al. (2021) [15] explicitly state that there are differences across polymer types and uses and that the range of $3 \%$ to $7 \%$ "does not cover brominated flame retardants, which are used at around 20\% (e.g. BDE-209 in PE [138]), nor plasticisers, which are used in PVC at 33\% on average [138]." Gouin himself shows in his Table 1 percentages of additives used across polymer types, easily proving the numbers stated by Andrade et al. (2021) to be rather on the low end of possible total additive concentrations found. There is therefore no reason to discredit the statements and numbers of Andrade et al. (2021) [15], as done in the Perspective with the sentence "Caution should thus be used not to overinterpret the significance of the estimates reported by Andrade et al. [133]."

6) Fishing net debris does not necessarily have to be from a local source

It is also argued in the Perspective that fishing- and shipping-related materials might be the main source of plastic debris and MP in both surface waters and sediment and that "shipping and/or fishing activity off the coast of remote islands that result in the release and subsequent beaching of plastic debris on their beaches, would, ... reflect a local source." Here, the general assumption that fishing- and shipping-related materials are an important 
source of plastic debris in the offshore ocean seems to be correct. Lebreton et al. (2018) [2] showed that $52 \%$ of the total floating plastic mass in the Great Pacific Garbage Patch is composed of fishing nets, ropes and plastic lines and $47 \%$ of hard plastics, sheets and films. However, a key point in this context is that fishing debris does not automatically have to be from local sources. Here, we modeled the travel distance and travel time of plastic debris stranding on the beaches of Marion Island and Gough Island, two remote islands located in the Sub-Antarctic Indian Ocean and Southern Atlantic Ocean, respectively, where high concentrations of chemical additives have been detected in the preen gland oil of birds [23]. Details on the applied ocean circulation model, the two scenarios investigated and the results are provided in the Supplementary Information. In brief, the model shows that plastic debris from river sources is very unlikely to reach Marion Island. Plastic debris from fishing sources reaching Marion Island originated mainly from areas south of the American continent and fishing grounds near Antarctica. The mean direct distance from sources is $5500 \mathrm{~km}$ (range 3250 to 7250 $\mathrm{km})$. Less than $7 \%$ of the plastic came from local fishing grounds, west of the island with distances to sources less than $1000 \mathrm{~km}$. For Gough Island, the model shows that more than $99 \%$ of the debris from river sources mostly originated from Brazilian rivers, located more than 3000 $\mathrm{km}$ away. Plastic debris from fishing sources originated mainly from fishing grounds off the coast of Argentina and travelled on average $4000 \mathrm{~km}$ (95 percentile 3000 to $5000 \mathrm{~km}$ ). These results clearly show that fishing debris does not necessarily have to be from a local source and can undergo LRT. Consequently, plastic-associated chemicals can undergo LRT as well.

7) The fact that much of the plastic debris from landbased sources remains near the coast does not mean that plastic debris cannot undergo LRET

It is also argued in the Perspective that MPs tend to accumulate in the vicinity of their emission sources, based for example on data from Turrell (2020) [24], "who report results of a model describing the sources of marine plastic litter and MPs to the Scottish Atlantic and North Sea Coast, which are dominated from sources related to littering along the Scottish coast". The statement is in line with modelling results from Onink et al. (2021) [25], who showed that at least 77\% of the buoyant marine plastic debris remain within 10 $\mathrm{km}$ of the model coastline and that only a small fraction escapes to the open ocean. However, there are two important points here: (i) Onink et al. (2021) [25] stated that the local fraction of beached buoyant marine plastic debris is relatively low for islands and (ii) even if much of the plastic remains near the coast, there is still a proportion that is transported into the open ocean and eventually over long distances. The results of Turrell (2020) [24] and Onink et al. (2021) [25] therefore do not point against the potential of plastic debris to undergo long-range environmental transport. There is additional evidence from monitoring studies that plastic debris undergoes LRET. The International Pellet Watch has shown that plastic pellets, although they derived from land-based sources, occur on beaches of remote and desert islands such as Macquarie Island and Henderson Island [26].

8) The call for better mechanistically-based models is justified, but the existing models describe the transport at least for large fragments in an acceptable way

At several points in the Perspective, it is emphasised that not enough is known about the fate and transport of MPs and chemical additives in MPs to decide whether or not MPs and chemical additives in MPs are able to undergo LRET. It is therefore suggested that "the development and application of mechanistically-based models and the acquisition of reliable and consistent monitoring data are urgently needed to better identify and characterize the sources, sinks and environmental fate processes of MPs." We agree that better mechanistic models are needed to understand the fate of MPs. Considerations of the size, shape and surface-area to volume ratio are very important to understand the presence of small particles at the surface of the ocean $[27,28]$. Particularly, the surface-area to volume ratio determines how a particle's floatability is impacted by biofouling from organisms or aggregation with natural colloids [29]. These processes are rarely considered in 2D transport models where every particle moves with the surface current. This is, however, not so much of a problem when large floating plastics are modeled as they maintain very high rising velocities. Large positively buoyant plastic fragments, with their smaller surface-area to volume ratios, are less prone to sinking than MPs, so that studying their dispersal over a long period of time as we do here, around one year of travel at least, is acceptable. There are still many ways to improve the models also for large plastic debris e.g. by including an interface between wind and current drag, including stokes drift, beaching and others, but the models that exist are able to describe the transport of large plastic fragments, including their LRET, in a sufficient way. For example, the modeled accumulation zones are located in the areas where high plastic concentrations have been found empirically [30].

9) Perspective calls for points that have already been investigated 
Finally, we would like to point out that the Perspective often calls for research into topics that have already been investigated. For example, it is stated "If we consider a simplistic model, whereby the relative differences in density between PVC and PE are used as parameters that influence mobility, with the density of PVC $>\mathrm{PE}$, then the relative importance of PVC to act as a LRET vector of PACs will be minimal, assuming that the greater density of PVC limits mobility and potential exposure to locations near emission sources. For plastic additive chemicals that may be associated with PE, on the other hand, and for which greater mobility can be assumed based on the simplistic model applied here, we may wish to further consider the influence of kinetic processes, such as leaching rates, which are likely to increase as particle size decreases or, alternatively, as surface area increases." However, Andrade et al. (2021) [15] have looked exactly into this point and concluded "Highest leaching rates are therefore expected for small PE fragments. According to the equations from Endo et al. [26], the desorption half-life from PE for substances with a $\log K_{\text {Ow }}$ between 5.5 and 7 will be between 1 and 38 years, assuming medium-turbulent water (aqueous boundary layer $100 \mu \mathrm{m})$. Phthalates have been shown to leach from plastic materials; with $80-120 \mathrm{ng} \mathrm{g}^{-1}$ plastic over a period of 90 days, only a small share of their overall content $(1-5 \mathrm{wt} \%)$ is released in the first 3 months of exposure [91]. This shows that leaching is a relevant process but also that considerable fractions of the additives remain available for long-range transport with the plastic matrix." Thus, the Perspective often asks for more data or insights but dismisses available information.

All of the above points detract from the value of the Perspective as a reliable source, as many of the conclusions are based on inaccurate assumptions and cherrypicking of available information. Therefore, we think that the Perspective should not be used in discussions of the plastic-driven LRET of chemical additives.

\section{Supplementary Information}

The online version contains supplementary material available at https://doi. org/10.1186/s43591-021-00021-z

Additional file 1. Supplementary Information for the Correspondence regarding the Perspective "Addressing the importance of microplastic particles as vectors for long-range transport of chemical contaminants: perspective in relation to prioritizing research and regulatory actions"\#.

Acknowledgements

Not applicable.

Authors' contributions

All authors contributed to the writing of the manuscript. The author(s) read and approved the final manuscript.
Funding

No funding was received for this work.

Availability of data and materials

Not applicable.

\section{Declarations}

\section{Competing interests}

The authors declare that they have no competing interests.

\section{Author details}

${ }^{1}$ Institute of Biogeochemistry and Pollutant Dynamics, ETH Zürich, 8092 Zürich, Switzerland. ${ }^{2}$ Department of Cell Toxicology, UFZ Leipzig-Halle, 04318 Leipzig, Germany. ${ }^{3}$ Norwegian Institute for Air Research (NILU), N-9296 Tromsø, Norway. ${ }^{4}$ Institute for Arctic and Marine Biology, UiT The Arctic University of Norway, N-9037 Tromsø, Norway. ${ }^{5}$ The Ocean Cleanup, 3014, $\mathrm{JH}$, Rotterdam, The Netherlands. ${ }^{6}$ The Modelling House, Raglan 3225, New Zealand. ${ }^{7}$ RECETOX, Masaryk University, 62500 Brno, Czech Republic.

Received: 18 November 2021 Accepted: 7 December 2021

Published online: 27 January 2022

\section{References}

1. Gouin T. Addressing the importance of microplastic particles as vectors for long-range transport of chemical contaminants: perspective in relation to prioritizing research and regulatory actions. Microplast Nanoplast. 2021;1(1): 14. https://doi.org/10.1186/s43591-021-00016-w.

2. Lebreton L, Slat B, Ferrari F, Sainte-Rose B, Aitken J, Marthouse R, et al. Evidence that the great Pacific garbage patch is rapidly accumulating plastic. Sci Rep. 2018;8(1):1-15. https://doi.org/10.1038/s41598-018-22939-w.

3. Cózar A, Echevarría F, González-Gordillo Jl, Irigoien X, Úbeda B, HernándezLeón S, et al. Plastic debris in the Open Ocean. Proc Natl Acad Sci. 2014; 111(28):10239-44. https://doi.org/10.1073/PNAS.1314705111.

4. Isobe A, Uchida K, Tokai T, Iwasaki S. East Asian seas: a hot spot of pelagic microplastics. Mar Pollut Bull. 2015;101(2):618-23. https://doi.org/10.1016/j. marpolbul.2015.10.042.

5. Lobelle D, Kooi M, Koelmans AA, Laufkötter C, Jongedijk CE, Kehl C, et al. Global modeled sinking characteristics of biofouled microplastic. J Geophys Res Ocean. 2021;126(4):1-15. https://doi.org/10.1029/2020jc017098.

6. Matsuguma $\mathrm{Y}, \mathrm{T}$ Takada $\mathrm{H}$, Kumata H, Kanke H. Microplastics in sediment cores from Asia and Africa as indicators of temporal trends in plastic pollution. Arch Environ Contam Toxicol. 2017;73(2):230-9. https://doi.org/1 0.1007/s00244-017-0414-9.

7. Nakano H, Arakawa H, Tokai T. Microplastics on the sea surface of the semiclosed Tokyo Bay. Mar Pollut Bull. 2020;2021(162):111887. https://doi.org/1 0.1016/j.marpolbul.2020.111887,.

8. Dibke C, Fischer M, Scholz-Böttcher BM. Microplastic mass concentrations and distribution in German bight waters by pyrolysis-gas chromatographymass spectrometry/Thermochemolysis reveal potential impact of marine coatings: do ships leave skid Marks? Environ Sci Technol. 2021;55(4):228595. https://doi.org/10.1021/acs.est.0c04522.

9. Schernewski G, Radtke H, Hauk R, Baresel C, Olshammar M, Osinski R, et al. Transport and behavior of microplastics emissions from urban sources in the Baltic Sea. Front Environ Sci. 2020;8:1-17. https://doi.org/10.3389/fenvs.2 020.579361

10. Zarfl C, Matthies M. Are marine plastic particles transport vectors for organic pollutants to the Arctic? Mar Pollut Bull. 2010;60(10):1810-4. https://doi. org/10.1016/j.marpolbul.2010.05.026.

11. Bakir A, O'Connor IA, Rowland SJ, Hendriks, AJ, Thompson RC. Relative Importance of Microplastics as a Pathway for the Transfer of Hydrophobic Organic Chemicals to Marine Life. Environ Pollut. 2016;219:56-65. https:// doi.org/10.1016/j.envpol.2016.09.046.

12. Gouin T, Roche N, Lohmann R, Hodges G. A thermodynamic approach for assessing the environmental exposure of chemicals absorbed to microplastic. Environ Sci Technol. 2011;45(4):1466-72. https://doi.org/10.1 021/es1032025

13. Koelmans AA, Bakir A, Burton GA, Janssen CR. Microplastic as a vector for Chemicals in the Aquatic Environment: critical review and model-supported reinterpretation of empirical studies. Environ Sci Technol. 2016;50(7):331526. https://doi.org/10.1021/acs.est.5b06069. 
14. Yeo BG, Takada H, Yamashita R, Okazaki Y, Uchida K, Tokai T, et al. PCBs and PBDEs in microplastic particles and zooplankton in open water in the Pacific Ocean and around the coast of Japan. Mar Pollut Bull. 2020;151:110806. https://doi.org/10.1016/..marpolbul.2019.110806.

15. Andrade H, Glüge J, Herzke D, Ashta NM, Nayagar SM, Scheringer M. Oceanic long-range transport of organic additives present in plastic products: an overview. Environ Sci Eur. 2021;33(1):85. https://doi.org/10.11 86/s12302-021-00522-x.

16. Seymour MD. The Biodegradation of Particulate Organic Matter in Saltwater Media. Master Thesis, Rice University; 1977.

17. Tanaka K, Takada H, Yamashita R, Mizukawa K, Fukuwaka MA, Watanuki Y. Facilitated leaching of additive-derived PBDEs from plastic by seabirds stomach oil and accumulation in tissues. Environ Sci Technol. 2015;49(19): 11799-807. https://doi.org/10.1021/acs.est.5b01376.

18. Tanaka K, Watanuki Y, Takada H, Ishizuka M, Yamashita R, Kazama M, et al. In Vivo Accumulation of Plastic-Derived Chemicals into Seabird Tissues. Curr. Biol. 2020;30(4):723-8.e3. https://doi.org/10.1016/j.cub.2019.12.037.

19. Ruczyńska W, Szlinder-Richert J, Nermer T. The occurrence and distribution of Nonylphenols and Nonylphenol Ethoxylates in different species of fish. Environ Sci Process Impacts. 2020;22(4):1057-70. https://doi.org/10.1039/ c9em00584f.

20. Corrales J, Kristofco LA, Baylor Steele W, Yates BS, Breed CS, Spencer Williams E, et al. Global Assessment of Bisphenol a in the Environment: Review and Analysis of Its Occurrence and Bioaccumulation. DoseResponse. 2015;13(3). https://doi.org/10.1177/1559325815598308.

21. Denghel H, Hiller J, Leibold $E_{1}$ Göen T. Human metabolism and kinetics of the UV absorber 2-(2H-Benzotriazol-2-YI)-4,6-Di-Tert-Pentylphenol (UV 328) after Oral administration. Arch Toxicol. 2021;95(8):2677-90. https://doi.org/1 0.1007/s00204-021-03093-1.

22. Environment and Climate Change Canada. Screening Assessment Report on Phenol, 2-(2H-Benzotriazol-2-Yl)-4,6-Bis(1,1- Dimethylpropyl)- (BDTP); Environment and Climate Change Canada \& Health Canada; 2016.

23. Yamashita R, Hiki N, Kashiwada F, Takada H, Mizukawa K, Hardesty BD, et al. Plastic Additives and Legacy Persistent Organic Pollutants in the Preen Gland Oil of Seabirds Sampled across the Globe. Environ Monit Contam Res. 2021;1:20210009. https://doi.org/10.5985/emcr.20210009.

24. Turrell WR. Estimating a regional budget of marine plastic litter in order to advise on marine management measures. Mar Pollut Bull. 2020;150:110725. https://doi.org/10.1016/.jmarpolbul.2019.110725.

25. Onink V, Jongedijk CE, Hoffman MJ, van Sebille E, Laufkötter C. Global Simulations of Marine Plastic Transport Show Plastic Trapping in Coastal Zones. Environ Res Lett. 2021;16(6):1-13. https://doi.org/10.1088/1748-932 6/abecbd.

26. IPW. International Pellet Watch. Pollution Map on Google Earth. http://www. pelletwatch.org/gmap/. Accessed 16 Nov 2021.

27. Kooi M, Reisser J, Slat B, Ferrari FF, Schmid MS, Cunsolo S, et al. The effect of particle properties on the depth profile of buoyant plastics in the ocean. Sci Rep. 2016;6:1-10. https://doi.org/10.1038/srep33882.

28. Kowalski N, Reichardt AM, Waniek JJ. Sinking rates of microplastics and potential implications of their alteration by physical, biological, and chemical factors. Mar Pollut Bull. 2016;109(1):310-9. https://doi.org/10.1016/j. marpolbul.2016.05.064.

29. Ryan PG. Does size and buoyancy affect the long-distance transport of floating debris? Environ Res Lett. 2015;10(8):84019. https://doi.org/10.1088/1 748-9326/10/8/084019.

30. Lebreton LCM, Greer SD, Borrero JC. Numerical modelling of floating debris in the World's oceans. Mar Pollut Bull. 2012;64(3):653-61. https://doi.org/10.1 016/j.marpolbul.2011.10.027.

\section{Publisher's Note}

Springer Nature remains neutral with regard to jurisdictional claims in published maps and institutional affiliations.

\section{Submit your manuscript to a SpringerOpen ${ }^{\circ}$ journal and benefit from:}

- Convenient online submission

- Rigorous peer review

- Open access: articles freely available online

- High visibility within the field

- Retaining the copyright to your article

Submit your next manuscript at $\boldsymbol{\nabla}$ springeropen.com 